\title{
Agro-Residues: Surface Treatment and Characterization of Date Palm Tree Fiber as Composite Reinforcement
}

\author{
Elsayed A. Elbadry \\ Mining and Metallurgical Engineering Department, Faculty of Engineering, Assiut University, Asyut 71515, Egypt \\ Correspondence should be addressed to Elsayed A. Elbadry; elsayed.ahmed@eng.au.edu.eg
}

Received 18 June 2014; Revised 1 October 2014; Accepted 12 November 2014; Published 23 November 2014

Academic Editor: Nikhil Gupta

Copyright (c) 2014 Elsayed A. Elbadry. This is an open access article distributed under the Creative Commons Attribution License, which permits unrestricted use, distribution, and reproduction in any medium, provided the original work is properly cited.

\begin{abstract}
The aims of this research are to investigate the effect of different surface treatment methods on the different properties of date palm fiber (DPF) compared to raw DPF fibers such as surface morphology, density, thermal stability, and tensile properties. The first surface treatment is called surface hand cleaning which can be carried out by cleaning the fibers by soft sand cloth; the second one is the same as the first one after DPF heat treatment in the furnace at $100^{\circ} \mathrm{C}$ for $1.5 \mathrm{~h}$ and the third one is by chemical treatment with $1 \% \mathrm{NaOH}$ at $100^{\circ} \mathrm{C}$ for $1 \mathrm{~h}$. The results showed that the mechanical performance of DPF was enhanced by the different treatments and the chemical treatment has pronounced effect on the behavior of DPF. Raw fibers showed the highest variability and presented the lowest value of Weibull modulus, whereas the fibers showed less variability by carrying out the different treatments. Moreover, using soda treatment cleans the fiber surface which causes fibrillation and therefore the tensile strength of the fibers increases.
\end{abstract}

\section{Introduction}

Due to environment and sustainability considerations, the development of high-performance materials made from natural resources is increasing worldwide. The greatest challenge in working with natural fiber reinforced plastic composites is lower $\mathrm{CO}_{2}$ emission compared to that of synthetic fibers [1]. The application of natural composites is being targeted in various fields due to the environmental and economic benefits which could be used in automotive industry as interior parts and in constructions sector such as walls and roofs. The use of natural plant fibers as reinforcement in fiber-reinforced plastics is receiving more attention recently, because of their advantages such as renewability, low density, and high specific strength. However, there are some disadvantages associated with the use of natural fibers as reinforcement in polymer composites. These include the incompatibility between fibers and polymer matrices, tendency to form aggregates during processing and poor moisture resistance, and so forth [2-4].

Different natural fibers such as jute, coir, banana, straw, palm, and others have been previously investigated to be used as natural reinforcements in composites [5-9]. Moreover, natural fibers were used as natural hybrids by a proper combination of natural reinforcements, that is, hybridization as reported in [10-13].
Evaluation of the mechanical performance of natural fiber composites depends on the mechanical behavior of the natural fibers which depends on the climate and harvesting conditions, maturity, and different fiber extraction such as retting and disintegration [14]. Moreover, the structure, microfibrillar angle, cell dimensions, defects, and the chemical composition of fibers are the most important variables that determine the overall properties of the natural fibers [15]. Many problems occur at the interface between the fibers and the matrix due to incompatibility between them. Therefore the surface modification of the natural fibers by different treatment is one of interest areas of the current research to improve compatibility and interfacial bond strength. The surface of natural fibers is influenced by chemicals used in treatment and processing conditions.

Date palm fiber (DPF) is a natural woven mat of crossed fibers of different diameters surrounding the palm tree stem as shown in Figure 1. Historically, the date palm trees were cultivated by the old Egyptians (Pharaohs) to eat the date fruit and to use the palm fibers for making ropes, baskets, and other utensil uses and these trees are abundantly found in Egypt especially in desert region like new valley and Siwa oasis. Moreover, the palm tree has religious importance for Arab and Muslims as in the story of the mother of Jesus (the virgin) when she shook the palm tree to get the dates during 


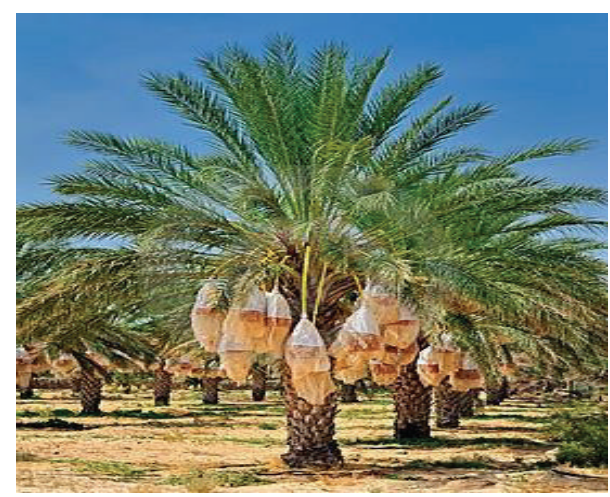

(a)

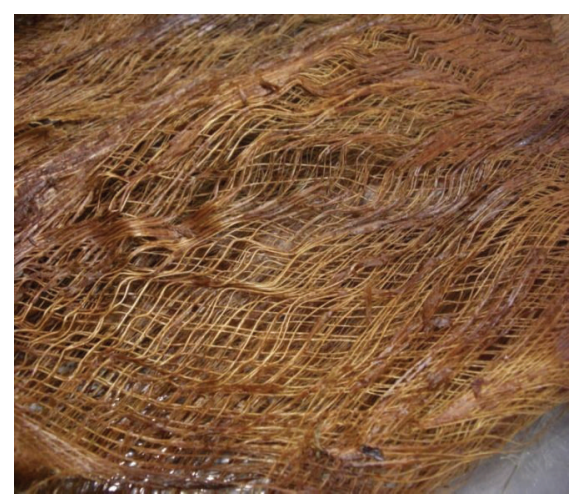

(b)

FIgURE 1: (a) Date palm tree and (b) date palm tree fibers that are surrounding the stems.

Jesus delivery. The possibility of using DPF reinforcement in composite manufacturing will help in opening new markets in Arab countries like UAE and Egypt for what is normally considered waste in low value products. The use of DPF as reinforcement in polymeric materials has been reported in few studies [16-19].

Using different physical treatment methods such as corona discharge and plasma and chemical surface treatment methods such as alkali, acetylation, and bleaching has direct effect on the changes in the surface structure of the natural fiber. These processes are cost effective and have been widely used to improve natural fiber surface properties [20]. The significance of chemically treated natural fibers was seen through the improvement of mechanical strength and dimensional stability of resultant composites [21]. Moreover, Effect of surface modification of bamboo cellulose fibers on mechanical properties of cellulose/epoxy composites was investigated by Lu et al. [22]. They indicated that The $\mathrm{NaOH}$ solution partly dissolved the lignin and amorphous cellulose, which resulted in splitting the fibers into smaller size and this led to more effective interfacial adhesion between the fiber and the matrix. Moreover, the surface modifications of jute/PBS composites as reported by Ku et al. [23] could remove surface impurities, increased surface roughness, and reduced diameter of jute fiber, and, subsequently, significantly increased the tensile strength and modulus of the composites but decreased breaking elongation. Shalwan and Yousif [24] indicated that the surface chemical treatment of the natural fibers assists to stabilize the bonding area between the fiber and the matrix which enhanced the ability of the fiber to carry the load under mechanical and tribological loadings.

The chemical treatments have significant drawbacks as the chemicals are costly and the used chemicals cannot be recycled and they have negative effects on the environment. Therefore, the aims of this research are to investigate the effect of different treatment methods that include mechanical treatment (surface hand cleaning) and heat assisted mechanical treatment compared to the chemical treatment on the behavior of DPF as natural fiber reinforcement. Different properties such as surface morphology, thermal stability, and mechanical properties have been investigated.

\section{Experimental}

2.1. Materials. Raw samples of DPF surrounding the date palm tree stems were collected by the Egyptian farmers from El Faiyum city, Egypt. These samples were washed by water and dried at room temperature and then preserved in bags and Sodium hydroxide was supplied by Kyoto Institute of Technology, Hamada Lab.

2.2. Fiber Preparation Methods. The natural mat consists of single fibers crossing each other. Due to their exposure to the natural environment, the natural fibers were contaminated with a large amount of sand and dusts. The samples were washed with fresh water and manually dismantled into bundles of virgin fibers; then the fibers were dried at room temperature for $24 \mathrm{~h}$ and cut to the desired length. These fibers are termed raw fiber and are referred to by symbol (A). In this study, fibers were treated by two main treatments: the first one is by mechanical treatment and the second is by chemical treatment. Mechanical treatment consists of two treatments: the first one is called surface hand cleaning which can be carried out by cleaning the fibers by soft sand cloth which are referred to by symbol (B) and the second one is the same as the first one after DPF heat treatment in the furnace at $100^{\circ} \mathrm{C}$ for $1.5 \mathrm{~h}$ which is referred to by symbol (C). The third one is by chemical treatment with $1 \% \mathrm{NaOH}$ at $100^{\circ} \mathrm{C}$ for $1 \mathrm{~h}$ and it was rinsed with fresh water and dried in the oven at $100^{\circ} \mathrm{C}$ at $1.5 \mathrm{~h}$ which is referred to by symbol (D). Finally, fibers were preserved in airtight bags to reduce moisture content.

2.3. Fiber Characterization. Fiber density was determined at room temperature measuring the pressure change of helium in a calibrated volume using AccuPyc 1330 Pycnometer, Shimazu, Japan. Three specimens were taken in each case. The thermal stability of DPF was characterized using thermogravimetric analyzer (TGA) and the measurements were performed in air atmosphere at a heating rate of $10^{\circ} \mathrm{C} / \mathrm{min}$ from room temperature to around $600^{\circ} \mathrm{C}$.

Single fibers were manually separated from the fiber bundles and specimens were prepared by gluing both fiber ends (about $50 \mathrm{~mm}$ ) by hard paper to prevent gripping damage. 


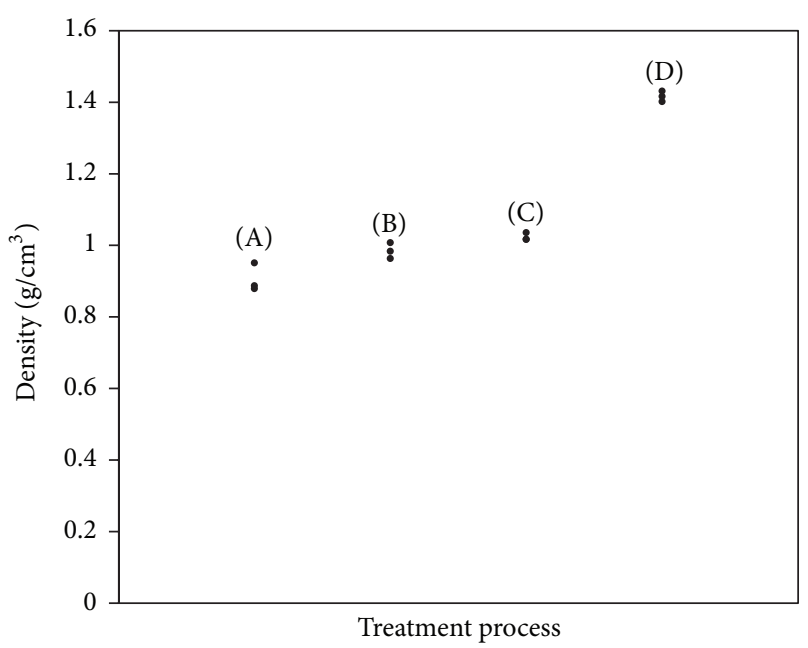

Figure 2: The effect of different surface treatment processes on the fiber density: (A) raw DPF, (B) surface hand treated DPF, (C) heat assisted-surface hand treated DPF, and (D) soda treated DPF.

30 single fibers were tested for each case with a gauge length of $100 \mathrm{~mm}$ with a crosshead speed $5 \mathrm{~mm} / \mathrm{min}$ at room temperature and the measurements were done using a universal Instron testing machine. Microscopic examinations were carried out using a JEOL-5200 scanning electron microscope (SEM). All specimens were mounted on steel holder using double-sided electrically conducting tabs and the specimens were coated with a thin layer of gold prior to SEM observations.

\section{Results and Discussion}

The effect of different surface treatments on the physical and mechanical characterization of DPF was investigated and the surface morphology of the fiber under different surface treatments was also examined.

3.1. Effect on DPF Density. The effect of different surface treatments on the fiber density is indicated in Figure 2. It can be seen that by carrying out all treatments the fiber density increases compared to the density of raw fiber due to the ability to remove the dusts and impurities. It can also be observed that when the fibers are subjected to the heat treatment before surface cleaning it can enhance sweeping the dusts and the contaminants from the fibers and, therefore, the density is enhanced. On the other hand, the chemical treatment has the largest value of the density due to the ability of the chemical solution to extract soluble products expected to be of low molecular weight. The chemical treatment is expected to have a significant effect on the fiber density by making fiber structure more compact (reducing lumen), and therefore fiber volume decreases and as a result of that the fiber density increases as reported in [18].

3.2. Effect on DPF Thermal Stability. It is well known that the thermal stability of the natural fiber under relatively high

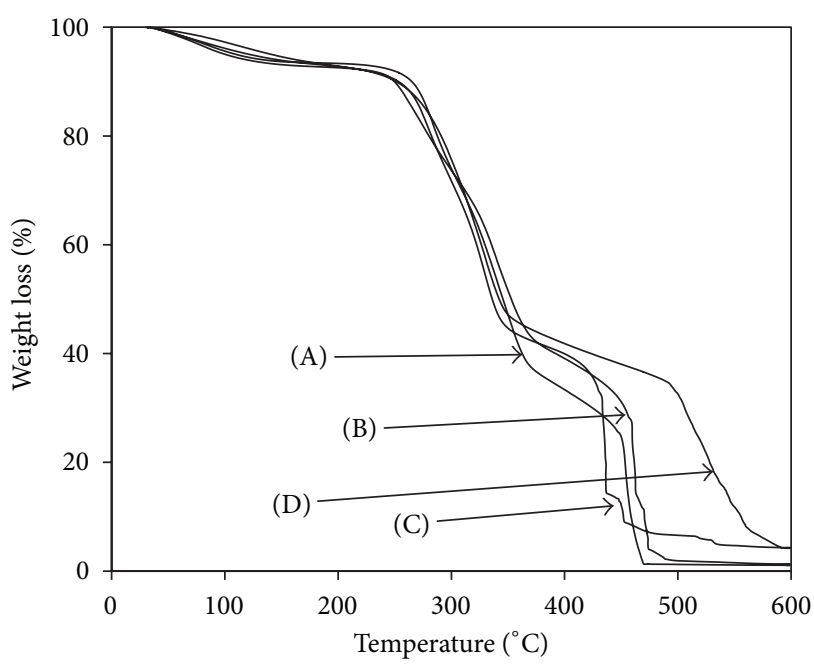

FIGURE 3: The effect of different surface treatment processes on the thermal stability of DPF: (A) raw DPF, (B) surface hand treated DPF, (C) heat assisted-surface hand treated DPF, and (D) soda treated DPF.

temperature is one of the most important factors in determining the use of natural fibers as reinforcement in the polymer matrix due to the high temperature resulting from the curing process of the polymer matrix. Figure 3 shows the results of thermal analysis of DPF under mechanical and chemical treatment compared to that of the raw fiber. It can be observed that the same behavior to thermal degradation for all treatment types of DPF as the temperature increased to $100^{\circ} \mathrm{C}$ which is a slight decrease in weight was observed and this may be due to the fiber moisture content. The weight loss shows a steady state behavior up to a temperature of around $250^{\circ} \mathrm{C}$, at which thermal degradation begins. These results are comparable to those obtained with other types of natural fibers such as kenaf, woof flour, and rice hulls and sisal [25]. The thermal behavior of chemically and mechanically treated DPF fibers is different as the temperature exceeds $250^{\circ} \mathrm{C}$. DPF treated by chemical treatment has higher thermal resistance to degradation than that of the other mechanical treatments and this may be due to the decrease in the hemicellulose content and the removal of components that degrade at lower temperatures due to the reaction with the soda solution which is not possible in the case of mechanical treatments.

3.3. Distribution Characterization of DPF. Cumulative diameter distribution of DPF under different treatments compared to that of raw fiber is shown in Figure 4 and 30 fiber samples were selected to carry out the experiment. The experimental diameter data were estimated from the following equation [26]:

$$
P(N)_{i}=\frac{i}{N+1},
$$

where $N$ is the total number of samples tested and $i$ is the number in ascendingly ordered diameter data.

It was easily noted that the distribution of the diameter shifted to the left side for all mechanical and chemical 


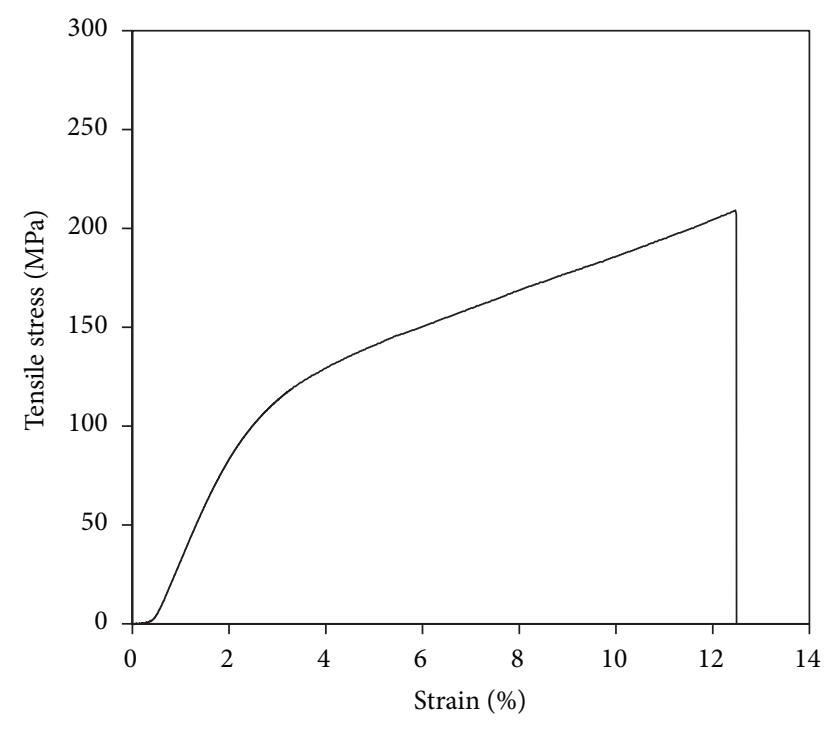

FIGURE 4: Stress-strain curve of a single DPF.

treatments compared to the distribution of raw fiber. The average diameter of the untreated fibers is $338 \mu \mathrm{m}$, whilst that of the fibers treated by surface hand treatment, surface hand treatment after heat treatment, and $\mathrm{NaOH}$ treatment is $309 \mu \mathrm{m}, 293 \mu \mathrm{m}$, and $288 \mu \mathrm{m}$, respectively. The bigger diameter of raw DPF results from layers of wax, dusts, impurities, and fatty substances on the fiber surface. The reduced diameter for different mechanical and chemical treatments is due to the removal of dusts, impurities, and other contaminants. The chemical treatment has more effect in reducing the diameter than the mechanical treatment because $\mathrm{NaOH}$ sweeps efficiently the wax, dusts, and impurities as well as the outer cementing layer of the fiber (lignin) and so the diameter significantly decreases by carrying out the chemical treatment by $\mathrm{NaOH}$.

3.4. Effect on DPF Tensile Properties. Figure 5 shows stressstrain curve of raw DPF fiber. The stress-strain curve for DPF is characterized by an initial linear region followed by a curvature indicating the increased rate of strain produced with increasing stress. This nonlinear region, following the initial portion of the stress-strain curve, has been assumed to be due to a collapse of the weak primary cell walls and delamination between fiber cells and this behavior of DPF is similar to other types of natural fibers [27].

The tensile properties including the tensile strength and modulus of single DPF fibers for different treatments compared to those of the raw fibers are indicated in Figures 6(a) and $6(\mathrm{~b})$, respectively. It can be observed that the average tensile strength and modulus of raw DPF fiber are around $176 \mathrm{MPa}$ and $5.5 \mathrm{GPa}$ which are close to the values of the coir and are comparable to other natural fibers [20]. It was known that a fiber with a larger cross-section area should have greater chance to have a bigger flaw and therefore, it is expected to be weaker than that with a smaller cross-section area [26]. In surface hand cleaning the diameter of the fiber

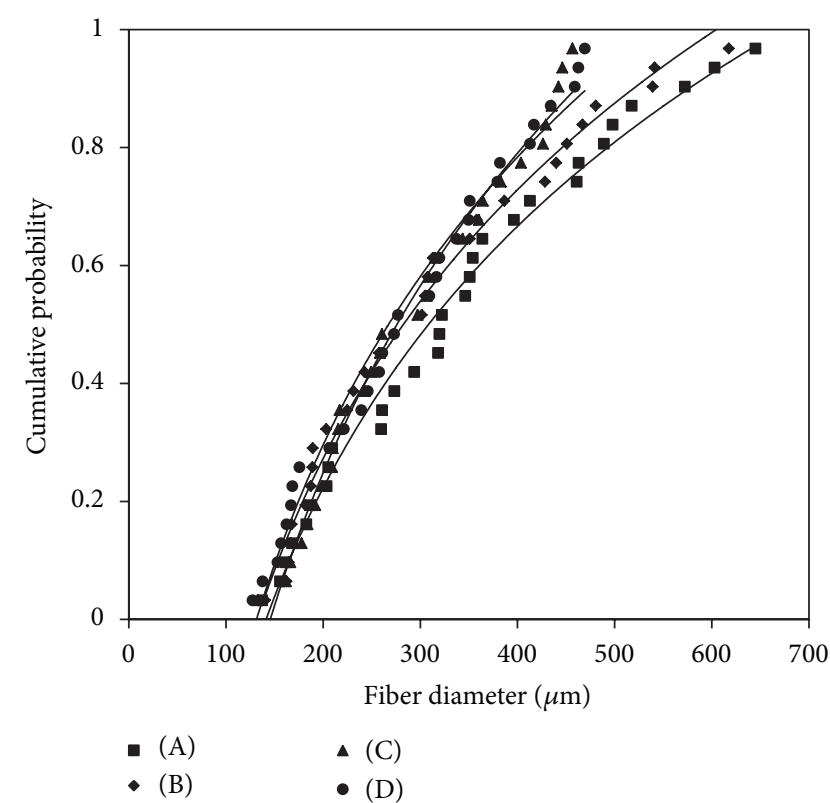

FIGURE 5: Cumulative diameter distribution of DPF under different surface treatment processes: (A) raw DPF, (B) surface hand treated DPF, (C) heat assisted-surface hand treated DPF, and (D) soda treated DPF.

decreases due to the removal of the dusts and impurities, so the tensile strength and modulus increase. Moreover, heat treatment of DPF fibers before surface cleaning helps in drying the fiber surface and so this enhances removing any contaminants and small fiber branches that are not capable of withstanding any tensile loads and therefore the tensile properties of the fibers increase. On the other hand, using the soda treatment leads to the highest tensile strength due to the reaction of fibers with the soda solution, making the fibrils more capable of rearranging themselves along the direction of the tensile deformation. Kabir et al. [21] reported that the fiber surface becomes more uniform due to the elimination of microvoids due to $\mathrm{NaOH}$ treatment and thus the stress transfer capacity between the ultimate cells improves and the fiber diameter is reduced and thereby increases the aspect ratio (length/diameter) and this increases effective fiber surface area for good adhesion with the matrix.

These results were validated by the surface morphology of DPF fibers under different treatment compared to that of raw data as shown in Figure 7. The surface morphology of raw DPF fibers is shown in Figure 7(a); in this figure the surface contains abundantly contaminants including small fiber branches and impurities such as dusts. These contaminants act as natural fiber flaws and they are expected to decrease the tensile properties of DPF fibers because these contaminants raise the diameter of the fibers and cannot sustain any tensile loads. Moreover, these contaminants are expected to decrease the compatibility between the fiber reinforcements and the polymer matrix in the composites which reduces adhesion at the interface between the fibers and the matrix, thus reducing stress transfer between the fiber and the matrix. The surface morphology of DPF fibers after being treated by surface hand 


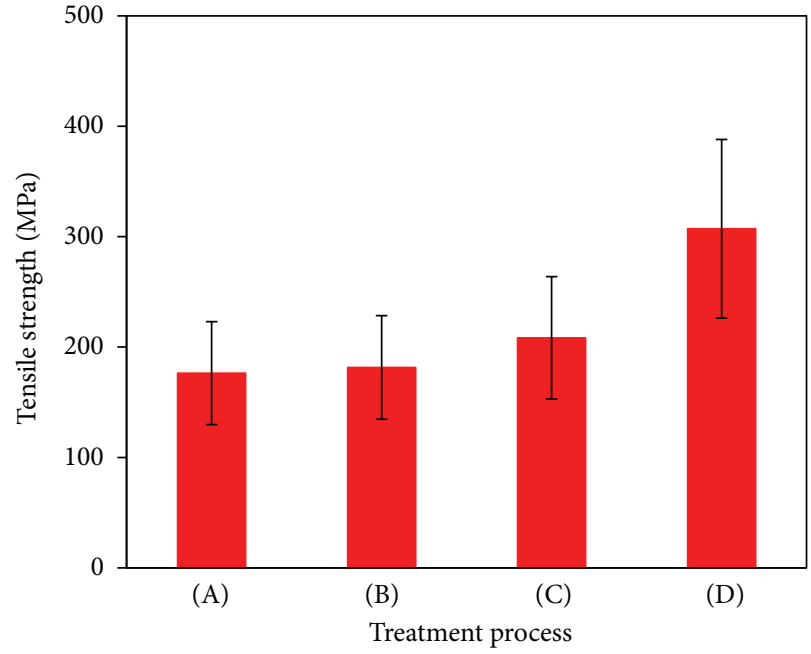

(a)

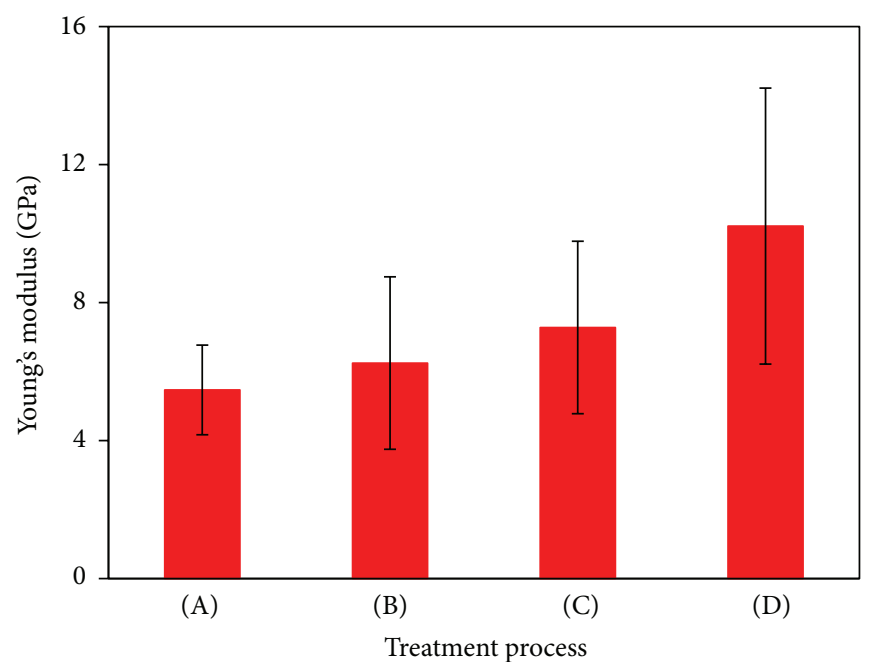

(b)

FIGURE 6: The effect of different surface treatment processes on (a) tensile strength and (b) Young's modulus of DPF: (A) raw DPF, (B) surface hand treated DPF, (C) heat assisted-surface hand treated DPF, and (D) soda treated DPF.

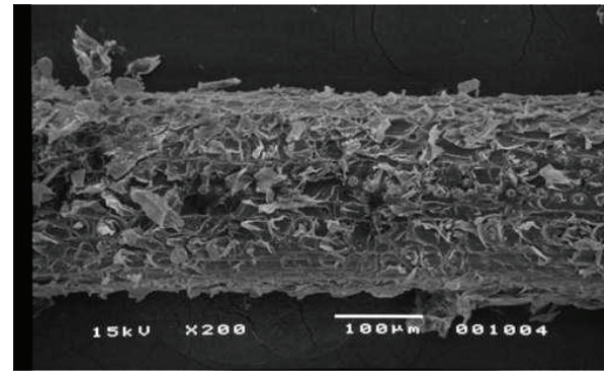

(a)

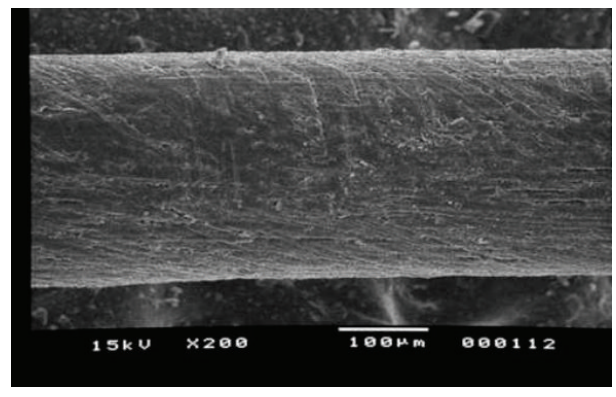

(c)

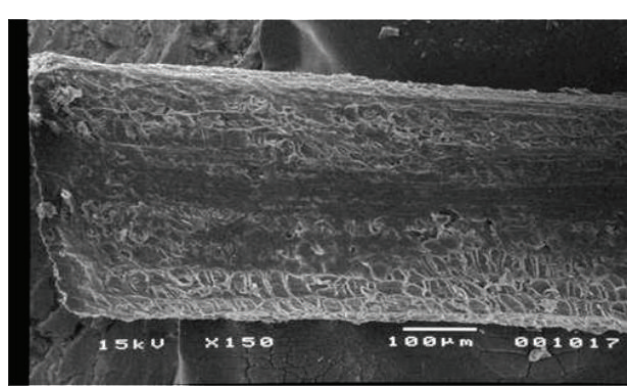

(b)

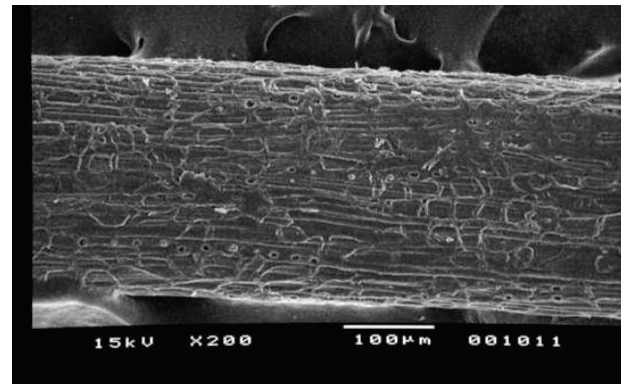

(d)

FIGURE 7: SEM micrographs of DPF: (a) raw DPF, (b) surface hand treated DPF, (c) heat assisted-surface hand treated DPF, and (d) soda treated DPF.

cleaning indicates that the contaminants on the surface were removed and this decreases the fiber diameter as indicated in Figure 7(b). Moreover, the heat treatment of DPF fibers before surface cleaning enhances drying the fiber surface and this helps in removing small fiber branches that are not capable of withstanding any tensile loads and therefore the tensile properties of the fibers increase as shown in Figure 7(c). The surface morphology of DPF fibers after chemical treatment is shown in Figure 7(d) which indicates that using soda treatment cleans the fiber surface of wax and fatty substances and causes fibrillation which causes the breaking down of the composite fiber bundle into smaller fibers and therefore the tensile strength of the fibers increases as reported in [14, 28]. Moreover, it is anticipated that a smooth surface will facilitate extraction of the fiber from the matrix as reported in [19]. The surface morphology of chemically treated DPF fibers shows rougher surfaces than those of other treatments as shown in Figure $7(d)$, which are expected to increase the amount of energy required for extracting the fibers and pulling them out from the matrix in the composites. 
Moreover, SEM micrographs indicate that some grooves appear on the fiber surface and may be due to the chemical reaction between soda and the fiber. These surface grooves increase as the soda increases and may lead to weakening of the fiber if the concentration of soda reaches a certain limit as reported in [28]. It can be concluded that the chemical treatment has more pronounced effect on the physical and mechanical properties of DPF than that of the mechanical treatments; however, the selection between the mechanical and chemical treatment based on the cost and environmental issues is different. The mechanical treatment is very cheap and has no negative effect on the environmental impact compared to the chemical treatment in which the used chemicals are costly and cannot be recycled and have negative effects on the environment.

3.5. Weibull Distribution of the Tensile Strength of DPF. Weibull statistics were used to rank the relative fiber strength versus probability of failure of the fibers to obtain measure of the variability in fiber strength. According to the Weibull analysis, the probability of survival of a fiber at a stress, $\sigma$, is given by the following relation $[26,27,29]$ :

$$
P(\sigma)=\exp \left[-\left(\frac{\sigma}{\sigma_{0}}\right)^{m}\right],
$$

where $\sigma$ is the fiber strength for a given probability of survival, $m$ is the Weibull modulus, and $\sigma_{0}$ is defined as the characteristic strength of a unit which is also called Weibull scale parameter. The higher the value of Weibull modulus, the lower the variability in fiber strength. Ranking of the fiber strengths is performed by using an estimator given by

$$
P(\sigma)_{i}=1-\frac{i}{N+1}
$$

where $P(\sigma)_{i}$ is the probability of survival corresponding to the $i$ th strength value and $N$ is the total number of fibers tested.

Substituting (2) into (1) yields

$$
\ln \ln \left[\frac{N+1}{N+1-i}\right]=m \ln \sigma-m \ln \sigma_{0}
$$

where $m$ and $\sigma_{0}$ can be found from the slope and intercept of $\ln \ln [(N+1) /(N+1-i)]$ versus $\ln \sigma$.

Figure 8 shows the Weibull distribution of the tensile strength of DPF for raw and treated DPF and the calculated Weibull moduli obtained from the Weibull plots are given in Table 1. It can be easily noted that before DPF treatment, Weibull modulus for DPF is 3.7 and this value is similar to that of piassava and sisal as reported in [27] and is higher than that of jute, flax, curaua, and coir fibers as reported in $[26,27,30]$ and is lower than that of wool fibers and abaca [30, 31]. The Weibull modulus values for natural date palm fiber are much lower compared to that of synthetic fibers such as glass fiber which is around 40 as reported in [32]. This indicates the nonhomogeneous nature of natural fibers which in turn is due to the predominance of defects within their structures and due to irregular fiber diameter. On the other hand, the Weibull modulus of DPF after being treated with surface hand
TABLE 1: Calculated Weibull modulus of different treated DPF compared to that of raw DPF fiber.

\begin{tabular}{lc}
\hline Treatment & Weibull modulus \\
\hline Raw DPF (A) & 3.72 \\
Mechanical treatment (B) & 4.21 \\
Heat assisted mechanical treatment (C) & 4.28 \\
NaOH treatment (D) & 4.27 \\
\hline
\end{tabular}

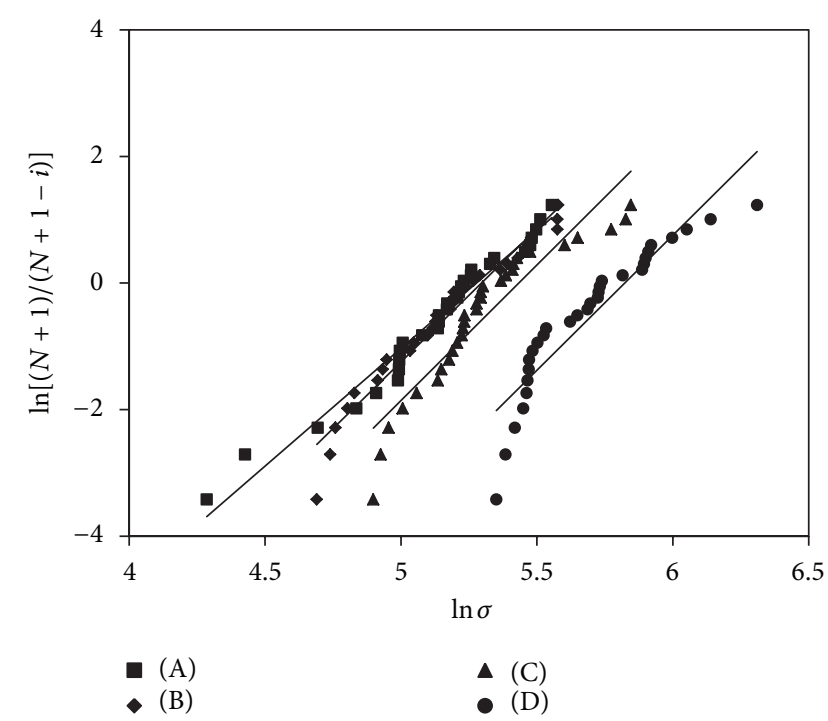

FIGURE 8: Weibull distribution of the tensile strength of DPF: (A) raw DPF, (B) surface hand treated DPF, $(C)$ heat assisted-surface hand treated DPF, and (D) soda treated DPF.

treatment, surface hand treatment after heat treatment, and $\mathrm{NaOH}$ treatment is 4.2, 4.8, and 4.8, respectively, as shown in Table 1. This indicates that the Weibull modulus is increased by carrying out the mechanical and chemical treatments and therefore higher variability in strength of raw fibers resulted compared to different treated fibers and the similar results were reported in [26], in which the Weibull modulus of the tensile strength of jute fiber was improved by chemical treatment. It can also be observed that the values of the Weibull modulus of mechanical and chemical treatment are almost the same as was shown in Table 1.

\section{Conclusion}

The aims of this research were to investigate the effect of different surface treatment methods on the behavior of date palm fiber (DPF) as natural fiber reinforcement including surface hand cleaning, heat assisted-surface hand treatment, and chemical treatment compared to that of raw fibers. The results of this research can be summarized in the following points.

(1) By carrying out all treatments the fiber density increases compared to the density of raw fiber due to the ability to remove the dusts and impurities. 
(2) The mechanical performance of DPF was enhanced by the different surface treatments and the chemical treatment has pronounced effect on the behavior of DPF.

(3) Heat treatment of DPF fibers before surface cleaning enhances drying the fiber surface and this helps in removing any contaminants and small fiber branches that are not capable of withstanding any tensile loads and therefore the tensile properties of the fibers increase.

(4) Raw fibers showed the highest variability and presented the lowest value of Weibull modulus, whereas the fibers showed higher value of Weibull modulus by carrying out the different treatment.

(5) Using soda treatment cleans the fiber surface of wax and fatty substances and causes fibrillation which causes the breaking down of the composite fiber bundle into smaller fibers and therefore the tensile strength of the fibers increases.

\section{Conflict of Interests}

The author declares that there is no conflict of interests regarding the publication of this paper.

\section{Acknowledgments}

The author would like to acknowledge Hamada Lab, Kyoto Institute of Technology, Japan, for the facilities to carry out different tests. Special thanks are due to Egyptian government and Assiut University for supplying the fund for this research.

\section{References}

[1] O. Faruk, A. K. Bledzki, H.-P. Fink, and M. Sain, "Biocomposites reinforced with natural fibers: 2000-2010," Progress in Polymer Science, vol. 37, no. 11, pp. 1552-1596, 2012.

[2] A. K. Mohanty, M. Misra, and L. T. Drazal, Natural Fibers, Biopolymers, and Biocomposites, Taylor \& Francis, New York, NY, USA, 2005.

[3] G. Koronis, A. Silva, and M. Fontul, "Green composites: a review of adequate materials for automotive applications," Composites Part B: Engineering, vol. 44, no. 1, pp. 120-127, 2013.

[4] F. P. La Mantia and M. Morreale, "Green composites: a brief review," Composites A, vol. 42, no. 6, pp. 579-588, 2011.

[5] P. J. Roe and M. P. Ansell, "Jute-reinforced polyester composites," Journal of Materials Science, vol. 20, no. 11, pp. 4015-4020, 1985.

[6] L. A. Pothan, S. Thomas, and N. R. Neelakantan, "Short banana fiber reinforced polyester composites: mechanical, failure and aging characteristics," Journal of Reinforced Plastics and Composites, vol. 16, no. 8, pp. 744-765, 1997.

[7] N. M. White and M. P. Ansell, "Straw-reinforced polyester composites," Journal of Materials Science, vol. 18, no. 5, pp. 15491556, 1983.

[8] S. V. Prasad, C. Pavithran, and P. K. Rohatgi, "Alkali treatment of coir fibres for coir-polyester composites," Journal of Materials Science, vol. 18, no. 5, pp. 1443-1454, 1983.
[9] S. A. S. Goulart, T. A. Oliveira, A. Teixeira, P. C. Miléo, and D. R. Mulinari, "Mechanical behaviour of polypropylene reinforced palm fibers composites," Procedia Engineering, vol. 10, pp. 20342039, 2011.

[10] M. Idicula, N. R. Neelakantan, Z. Oommen, K. Joseph, and S. Thomas, "A study of the mechanical properties of randomly oriented short banana and sisal hybrid fiber reinforced polyester composites," Journal of Applied Polymer Science, vol. 96, no. 5, pp. 1699-1709, 2005.

[11] P. Noorunnisa Khanam, M. Mohan Reddy, K. Raghu, K. John, and S. Venkata Naidu, "Tensile, flexural and compressive properties of sisal/silk hybrid composites," Journal of Reinforced Plastics and Composites, vol. 26, no. 10, pp. 1065-1070, 2007.

[12] M. Ramesh, K. Palanikumar, and K. H. Reddy, "Mechanical property evaluation of sisal-jute-glass fiber reinforced polyester composites," Composites Part B: Engineering, vol. 48, pp. 1-9, 2013.

[13] M. Boopalan, M. Niranjanaa, and M. J. Umapathy, "Study on the mechanical properties and thermal properties of jute and banana fiber reinforced epoxy hybrid composites," Composites Part B: Engineering, vol. 51, pp. 54-57, 2013.

[14] S. Kalia, B. S. Kaith, and I. Kaur, "Pretreatments of natural fibers and their application as reinforcing material in polymer composites-a review," Polymer Engineering and Science, vol. 49, no. 7, pp. 1253-1272, 2009.

[15] M. J. John and R. D. Anandjiwala, "Recent developments in chemical modification and characterization of natural fiberreinforced composites," Polymer Composites, vol. 29, no. 2, pp. 187-207, 2008.

[16] H. Kaddami, A. Dufresne, B. Khelifi et al., "Short palm tree fibers-thermoset matrices composites," Composites Part A: Applied Science and Manufacturing, vol. 37, no. 9, pp. 1413-1422, 2006.

[17] R. Kahraman and B. F. Abu-Sharkh, "Moisture diffusion into palm/polypropylene composites in sodium chloride solutions," Journal of Applied Polymer Science, vol. 106, no. 4, pp. 25752579, 2007.

[18] A. Al-Khanbashi, K. Al-Kaabi, and A. Hammami, "Date palm fibers as polymeric matrix reinforcement: fiber characterization," Polymer Composites, vol. 26, no. 4, pp. 486-497, 2005.

[19] K. Al-Kaabi, A. Al-Khanbashi, and A. Hammami, "Date palm fibers as polymeric matrix reinforcement: DPF/polyester composite properties," Polymer Composites, vol. 26, no. 5, pp. 604613, 2005.

[20] X. Li, L. G. Tabil, and S. Panigrahi, "Chemical treatments of natural fiber for use in natural fiber-reinforced composites: a review," Journal of Polymers and the Environment, vol. 15, no. 1, pp. 25-33, 2007.

[21] M. M. Kabir, H. Wang, K. T. Lau, and F. Cardona, "Chemical treatments on plant-based natural fibre reinforced polymer composites: an overview," Composites Part B: Engineering, vol. 43, no. 7, pp. 2883-2892, 2012.

[22] T. Lu, M. Jiang, Z. Jiang, D. Hui, Z. Wang, and Z. Zhou, "Effect of surface modification of bamboo cellulose fibers on mechanical properties of cellulose/epoxy composites," Composites B, vol. 51, pp. 28-34, 2013.

[23] H. Ku, H. Wang, N. Pattarachaiyakoop, and M. Trada, "A review on the tensile properties of natural fiber reinforced polymer composites," Composites Part B: Engineering, vol. 42, no. 4, pp. 856-873, 2011. 
[24] A. Shalwan and B. F. Yousif, "In state of art: mechanical and tribological behaviour of polymeric composites based on natural fibres," Materials \& Design, vol. 48, pp. 14-24, 2013.

[25] M. Tajvidi and A. Takemura, "Effect of fiber content and type, compatibilizer, and heating rate on thermogravimetric properties of natural fiber high density polyethylene composites," Polymer Composites, vol. 30, no. 9, pp. 1226-1233, 2009.

[26] X. Y. Liu and G. C. Dai, "Surface modification and micromechanical properties of jute fiber mat reinforced polypropylene composites," Express Polymer Letters, vol. 1, no. 5, pp. 299-307, 2007.

[27] M. E. A. Fidelis, T. V. C. Pereira, O. F. M. Gomes, F. A. Silva, and R. D. T. Filho, "The effect of fiber morphology on the tensile strength of natural fibers," Journal of Materials Research and Technology, vol. 2, no. 2, pp. 149-157, 2013.

[28] A. Alawar, A. M. Hamed, and K. Al-Kaabi, "Characterization of treated date palm tree fiber as composite reinforcement," Composites Part B: Engineering, vol. 40, no. 7, pp. 601-606, 2009.

[29] F. A. De Silva, N. Chawla, and R. D. T. Filho, "Mechanical behavior of natural sisal fibers," Journal of Biobased Materials and Bioenergy, vol. 4, no. 2, pp. 106-113, 2010.

[30] L. Peponi, J. Biagiotti, L. Torre, J. M. Kenny, and I. Mondragòn, "Statistical analysis of the mechanical properties of natural fibers and their composite materials. I. Natural fibers," Polymer Composites, vol. 29, no. 3, pp. 313-320, 2008.

[31] Y. Zhang, X. Wang, N. Pan, and R. Postle, "Weibull analysis of the tensile behavior of fibers with geometrical irregularities," Journal of Materials Science, vol. 37, no. 7, pp. 1401-1406, 2002.

[32] M. Elices and J. Llorca, Fiber Fracture, Elseveir Science Ltd, Oxford, UK, 2002. 

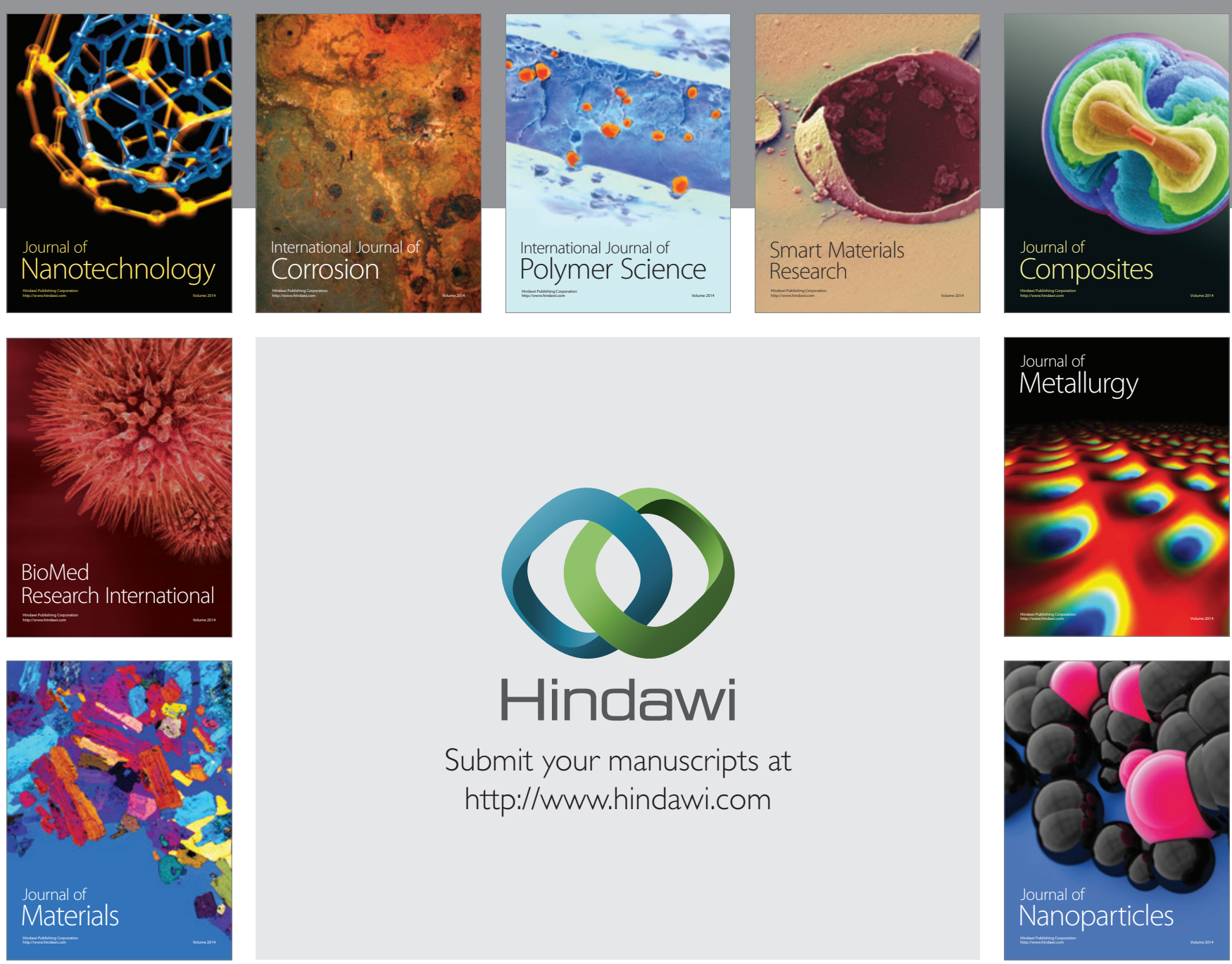

Submit your manuscripts at http://www.hindawi.com
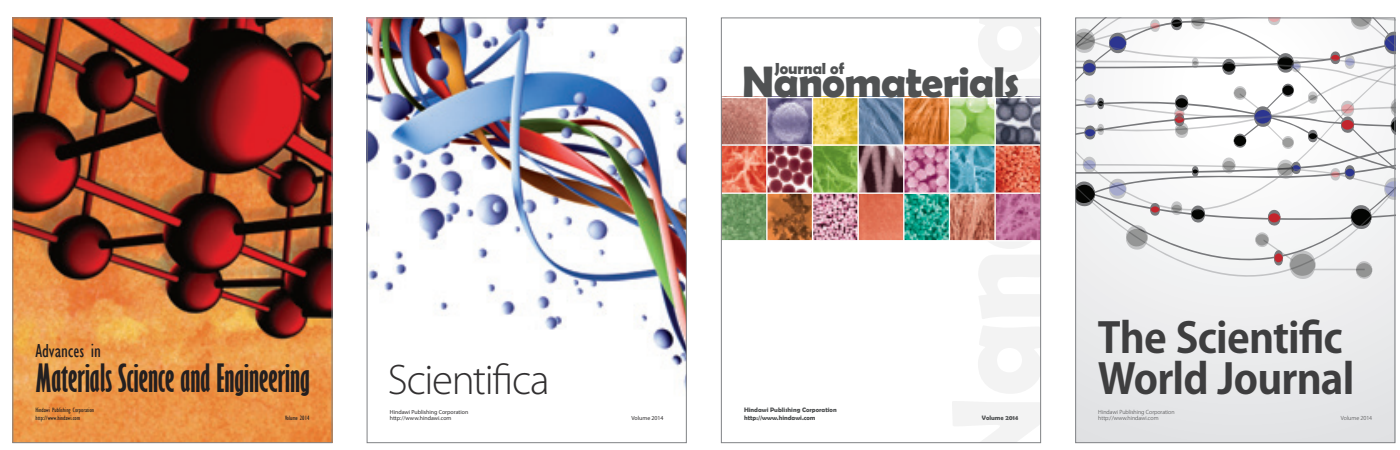

\section{The Scientific World Journal}
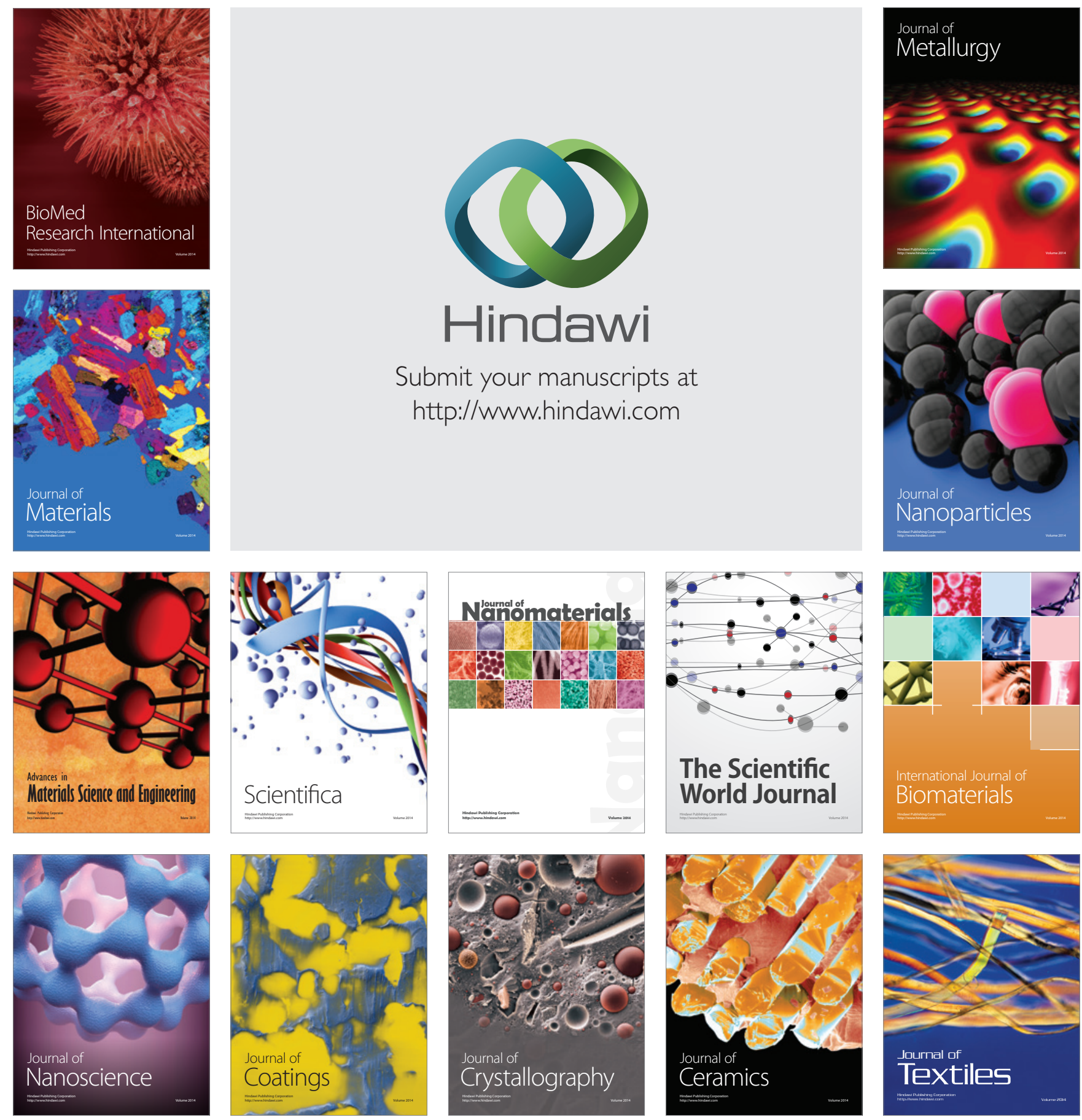